\title{
A Review Paper on ELT Articles Conducted on EFL Teachers' Perceptions, Practices and Challenges towards Communicative Language Teaching
}

\author{
Netsanet Haymanot Belete (MA in TEFL) \\ Email: netsanethaymanot@,gmail.com \\ Injibara University, Injibara, Ethiopia
}

\begin{abstract}
This seminar paper aimed at reviewing English language teaching (ELT) articles on EFL Teachers' perceptions, practices and challenges towards communicative language teaching (CLT).

\section{Introduction}

A seminar is the forum for academic discussion on some critical issues on the political, educational, social, economical and cultural hemispheres of the society. The seminar, which is a form of academic paper in institutions, has the function of bringing together small groups focusing on some particular subject, in which everyone present is requested to participate.

In seminar, numerous activities are performed. For instance, identifying the problem, reviewing articles, analyzing and synthesizing articles, writing proposals and writhing the final theses and dissertations are accompanied by seminar presentation. To write any scientific papers, researchers and practitioners first review and analyze the journals, articles and research papers so as to conduct a valid research.

Here, my special focus is the analysis of ELT articles based on their features; like, the title, research questions, objectives, participants, sampling and techniques of data analysis. I have selected three articles that focus on EFL teachers perceptions and practices on communicative language teaching (CLT).

The ultimate purpose of this paper is to review the selected ELT articles based on their basic constituents, and to compare and contrast the selected articles on the same focus. Apparently, when I evaluate, analyze and synthesize those selected ELT articles, 
In the following sections, I am going to review three articles on the teachers' perceptions and actual practices of CLT on EFL classes. The titles, authors and the publication years are highlighted and introduced here under.

The first article was conducted on Tunisian Secondary EFL School Teachers' perceptions regarding Communicative Language Teaching. This exploratory survey study was conducted by Asma Ounis and Tesnim Ounis in 2017. The aim of this article was to investigate secondary school EFL teachers' perceptions of CLT principles and practices in the Tunisian context. It also sought to explore EFL teachers' attitudes toward CLT as well as the difficulties they may encounter in implementing the approach in their classrooms.

The second articles focused on EFL Teachers' Attitudes towards Communicative Language Teaching in Taiwanese college. This explanatory article was studied by Ming Chang in 2011. The aim of this study was to investigate Taiwanese college teachers' attitudes toward CLT and the reasons behind their attitudes.

The third article was studied on Teachers' perceptions and challenges regarding the implementation of communicative language teaching (CLT) in Malaysian secondary schools. It was published by Reza Raissi and Fazirah Mohd in 2013. The purpose of this article is to investigate teachers' perceptions and challenges regarding CLT in Malaysian secondary schools.

The aforementioned articles are deeply reviewed and analyzed based on the frameworks and elements of a good article. These ELT articles are reviewed both individually and comparing and contrasting one another.

\section{Analysis One: Tunisian Secondary EFL School Teachers' perceptions regarding Communicative Language Teaching}

\section{Reviewing general introductions and statements of the problem}

As it is introduced before, this article has been conducted by Asma Ounis and Tesnim Ounis in 2017. Asma Ounis has completed his doctorate degree (Ph.D) in Applied Linguistics. On the other hand, Tesnim Ounis is candidate doctor and researcher in the field of Applied Linguistics. Both of them are members of the Laboratory on Approaches to Discourse and the Doctoral School in Letters, Arts and Humanities, Faculty of Letters and Humanities of Sfax, Tunisia. Both writers are teachers in Tunisian university and close friends. 
The title they raised is very interesting and crucial issue in our country, Ethiopia, also because the perceptions of ELT teachers are positive in the form of theory, but they do not do as expected. Even though TEFL teachers know the features of communicative language teaching (CLT) very well theoretically, they have limitations to apply in the classrooms. Therefore, the title is current issue on many countries and needs to be researched. Only knowing the concepts and theories of student centered methods of teaching like CLT is not a guarantee for sustain or bringing communicative competences among our students. Instead, teachers should practice CLT in their actual classrooms beyond their theoretical perspectives. However, the title is too narrow to reach on conclusions, because it focuses only on teachers perceptions toward CLT.

Having researched on only teachers' perception is not sufficient to conclude on CLT. Instead, if I had been a researcher of this article, I would have included the teachers' actual practice on CLT and the students' perceptions toward on CLTs also. By incorporating both the students' and teachers' perceptions and practices, I would have conducted a valid research which is free from bias. I know that research topics should be specific enough particularly in applied researches like action research, but for such article, it was nice if the authors include the students' perceptions and the teachers' practices on CLT. Anyways, the title is current and up to date in our teaching learning processes and very interesting issue though it has some limitations.

The abstract of this study includes important points which are found in the entire article. It is interesting and attractive to push the readers to read the whole study without losing interest because it summarizes necessary points and conclusions in the study. In relation to its introduction, the authors tried to introduce the title by stating the general introduction about CLT, and then they moved to their specific issue on perceptions and challenges to implement CLT. The researchers were initiated by observing the actual problem through experiencing it. After they observed the challenges to implement CLT, they tended to conduct on this issue.

\section{Reviewing research questions and objectives}

The study forwarded three basic questions to answer at the end of this article. Those research questions are open ended "Wh" questions that need appropriate conclusions and findings. The research questions are clear and researchable for the topic they raised. These questions enabled the researchers to design equivalent objective for the successful accomplishment of their study. Even, the questions dealt with not only the perceptions of EFL teachers but also the challenges to implement it for the students. For instance, let us have a look at two of the questions. 
1. What are EFL teachers' perceptions regarding the appropriateness of CLT in their classrooms?

2. What difficulties do Tunisian EFL teachers face when implementing CLT? (p. 7).

The first question dealt with the perceptions of the teachers on the appropriateness on their classrooms while the second one focused on the challenges or difficulties that EFL teachers face to implement CLT in their classrooms. So, it is inclusive and appropriate so as to conduct a good study. In basic researches, it is recommended to formulate "Wh" questions to make generalizations and conclusions. Therefore, the research questions were designed in a good manner.

In relation to the objectives of the study, the aim of this study was to investigate secondary school EFL teachers' perceptions of CLT principles and practices in their classrooms. When I evaluate the objectives of the article based on my perspective, the study didn't present objectives explicitly by giving its sub topic. As it is well known, in order to conduct a research, we should first have the intended objective. Without a clear objective, it is impossible to conduct a purposeful and appropriate research. Objectives should be explicitly presented since they are the core reasons to study. However, this study did not forward them directly in its own section. Fortunately, the authors designed and forwarded their intended objectives on the sub sections of abstract and research questions.

For example, in the abstract, they expressed, "The present study investigates secondary school EFL teachers' perceptions of CLT principles and practices in the Tunisian context. It seeks to explore EFL teachers' attitudes toward CLT as well as the difficulties they may encounter in implementing the approach in their classrooms." (p. 1). In addition to the above objectives, they added another specific objective by incorporating it with the research questions. "This study is set up to explore the Tunisian teachers' beliefs of the appropriateness of implementing the communicative approach in the classroom setting. " $(p, 7)$.

When I come across to the objective evaluation of the research objectives, based on those three implicit objectives, I want to confirm them since they are clear, manageable and researchable. The objectives were designed in a proper way by considering the basic research questions. They are equivalent with research questions in number. Particularly, the first general objective was formed properly. It includes the other two specific objectives. It was formed by considering the teachers' perceptions, principles and practices of CLT in their classrooms. It is inclusive enough 
to answer the research questions raised before. The specific objectives generated from the general objective, and they developed the general one by providing specific tasks so as to achieve the intended general objective.

\section{Reviewing the methods of the study}

In this study, the methodology which is related to the investigation of Tunisian EFL teachers' perceptions on CLT is presented. The methodology covers the research design, the participants, sampling size and sampling techniques, data collection instruments, data collection procedures and method of data analysis.

By nature, this study was exploratory survey research design which was not experimental. In this type of research design, the purpose is to explore ideas; theories, skills and knowledge form the current trends. It investigates a drop of knowledge or theory on the current situations or problems. Thus, the research design is appropriate with the research questions, objectives and findings in general.

The target populations of this study were the total number of Tunisian English language teachers of the secondary schools. Among those populations, the sample size constituted 30 EFL teachers who volunteered to take part in the study. Now, to start my review, it is better to imagine the total number of EFL teachers in Tunisian secondary schools. I imagine that there are very large numbers of EFL teachers in Tunisian secondary schools. On the contrary, the authors took only 30 participants in Tunisian setting, and they made generalizations by taking only 30 EFL teachers in all Tunisian secondary schools.

In my point of view, it is totally unrepresentative to make conclusions because they are very few participants among the total target population. Actually, the sampling size should be decided in different situations and it depends on the total target populations and the setting. We cannot easily limit the sampling size in a certain study; it depends on the population we have and the research design we do. If I had been them, I would have added more participants so as to reach to sound conclusions. Even though the study is exploratory survey research, researchers should have maximized their number of participants based on the teachers' proportions between the total populations and the participants. In fact, exploratory survey research studies will not require that much numbers of participants because they explore and make conclusions by few participants among the large number of populations. The purpose of survey research is to make generalizations by taking few participants as a sample. However, taking only 30 teachers is not 
sufficient to generalize the overall Tunisian EFL secondary school teachers because it is impossible and not acceptable to reach on generalizations.

In relation to sampling technique, the researchers selected non probability sampling technique. They simply picked voluntary EFL teachers to take part in the study. Now, it was the second mistake that they selected participants by using purposive sampling. In survey research, at least the participants should be selected by using probability sampling. Although we can use both probability and non probability sampling techniques based on the purpose, the situation and the nature of the study, in this study probability sampling techniques is more appropriate than purposive sampling. In order to reach sound conclusions, the participants should be heterogeneous and variety in sex, age, race, academic level, experience, attitudes and so on. By incorporating such varieties of participants, we can get a good result also.

Otherwise, by taking purposive sampling and also very few participants, it is unbelievable to conclude the findings. Actually, the study tried to make the participants divers in their qualification; like bachelor degree and masters degree, different work experiences, balanced sex, and different age levels; however, it is not sufficient to make the selection appropriate. To make my idea clear, probability sampling is relatively free from bias since we get diversified ideas and responses from heterogeneous groups of participants, but taking similar groups of participants produces similar ideas and responses; therefore, it is not generalizable in deed. If I had been the researcher of this study, I would have selected systematic random sampling or stratified random sampling to address equal chances for diversified all EFL teachers.

Therefore, selecting 30 EFL teachers by using convenient sampling is not appropriate to reach for good findings since they are not representative to all secondary school EFL teachers of Tunisia. They are not enough in number, and also the sampling technique is not as such appropriate.

Furthermore, the study used semi structured questions to collect data from participants. They asserted, "In order to address the purpose of this study, a combination of quantitative and qualitative data using a semi structured questionnaire was carried out." (p.1). The questionnaire is made up of two parts; the first part dealt with teachers' background information (age, gender, teaching experience and educational background), and the second part focused on teachers' perception of CLT principles and practices. The reason why questionnaire was selected for the study was the fact that it contained both close ended questions which are used to elicit a quick 
response, and open ended questions which provided opportunities for the respondent teachers to justify their perceptions freely.

Having expressed the features of the questionnaire above, let me now forward my suggestions on the data collecting instruments. As it is stated above, the study used only questionnaire which is both open ended and close ended questions. As a research, in order to make the study reliable and valid, we should use verities of data gathering tools. The more we use data collection tools, the more our study is reliable and valid. Even, we have to triangulate similar questions by using different data collection tools because if we use triangulation, we can cross check the responses again to decide on it.

On the contrary, this study used only questionnaire. So, how can we cross check the responses so as to make the research appropriate? It is not recommended to use only one tool to collect data because it has negative effects on the conclusions. They should have used other tools; like, observation, interview and focus group discussion for this study; they were appropriate if those tools were used. If I were them, I would use the above tools to get sufficient and variety of data from respondents.

To conclude, the way they applied the questionnaire is very good and appropriate, and they used questionnaires effectively by mixing both open ended and close ended questions. On the contrary, this tool is not sufficient to collect enough data from respondents. Although they applied the questionnaires appropriately, due to one type of data collecting instruments, the study was not reliable and valid because valid and reliable instruments made the study valid and reliable, also.

In relation to its method of data analysis, the study used a combination of both qualitative and quantitative data analysis methods. The study analyzed close ended questions by using quantitative methods of data analysis technique in percentages, numbers and tabulations, and Quantitative analysis was done through a statistical analysis of data using the Statistical Package for the Social Sciences (SPSS) software which is commonly used in applied linguistics and educational research. For example, number of participants who selected each item was calculated using frequency, the results were analyzed and tabulated and then they were converted into percentages.

On the other hand, open ended questions were analyzed by using qualitative method of data analysis technique in the form of expressions, narrations and descriptions. Qualitative analysis 
was carried out through an analysis of the results of the open ended questions. It is used to gain an understanding of underlying reasons and opinions of the teachers and to dive deeper into the problem.

Having gained information above, the study used mixed methods of data analyses to interpret the data well. Using both quantitative and qualitative methods of data analyses is helpful to get additional data towards the conclusions and the findings. As I have discussed before, it was nice if the researchers used other instruments, but if so, using mixed methods of data analyses is very good to get reliable data from the respondents. We can infer the conclusion by getting the responses of two types of questions by using mixed method of data analyses. Therefore, the data analyses techniques were appropriate for the study.

Additionally, the data collection procedure of this study relied on a simple random sampling method in the sense that the questionnaire was administered and shared on a Facebook page which exclusively associates and connects EFL teachers teaching at different schools in Tunisia. The researchers requested that the questionnaire should be completed by the secondary school teachers who were assured that all the data collected were for research purposes only. The survey was filled in by 30 teachers who sent it back to the researchers via e-mail. The process of data collection lasted approximately two weeks.

In the above data collection procedure, I understood that the questionnaire was held electronically. Although doing tasks in a sophisticated way electronically, it is not trustworthy to collect the research data via the participants' Facebook pages. What would happen if the respondents did not have Facebook pages or email addresses? Even, they might not see the questionnaires for weeks if they didn't use Facebook due to network problem and other social factors. They should have administered though printed paper physically to be filled with in an hour, and it was better to collect the responses by giving similar orientation for the participants instead of ordering them to do individually in different situations. It was also time consuming since the researchers collected responses from each participant. Another limitation went to its sampling techniques. It used non probability sampling by selecting voluntary teachers before in this section, but now it used simple random sampling. It was inconsistent and did not match one idea with others. Thus, the procedure is not appropriate, and it should be collected by physical contact and by providing printed questions for them at the same time in the same orientations. 
Generally, concerning to the methodology of the study, it incorporated interesting ideas although it had some limitations. The methodology went with the objectives and the research questions to reach on to the findings. It was clear enough that it clearly stated the participants, the research design, the sampling size and techniques, the data collection instruments and finally the method of data analysis techniques in advance. However, it is undeniable that the study had limitations on the data collection instruments, sampling size and sampling technique.

\section{Reviewing the study findings}

Before I evaluate the findings, and implications of the study, it is better to highlight the conclusion taken from the article by paraphrasing it.

In this study, the attitudes expressed by secondary school teachers seemed to be relatively consistent with the CLT principles and goals. This result reveals the gap between teachers' willingness to embrace CLT in their classes and the restrictions of the teaching context. Foremost, the majority of the teachers perceived factors such as number of class hours, teacher training courses for teachers, class size, exam system and lack of materials for communicative activities (p.13).

Having seen the above extraction from the conclusion, the study was an appropriate way to answer the research questions. The finding was directly related to the research questions, and it tried to answer them appropriately. Again, the study went along with the objectives of the study. Objectives are fully achieved by the conclusion of the study. The researchers accomplished their objective by providing appropriate findings, and they were successful in relation to the objectives and basic research questions. The findings of the researchers were directly generated from the objectives, and the study accomplished its intended objective by forwarding the teachers' perceptions and actual practices on CLT principle. Teachers had positive feeling towards CLT and its principles, but they faced different problems like class size, contact hour, exam system and so on to implement CLT in their classrooms.

The study tried to explore major obstacles that hinder the actual CLT implementations in the classrooms, but there were also other variables which hindered the implementations of CLT in the classrooms. So, in order to investigate any other variables, the study was gave chance to other studies on the same issue. They forwarded that another further studies were needed to find out other variables on this issue. 
Generally, the researchers tried to explore the perceptions of Tunisian secondary school teachers on CLT principles. They designed appropriate objectives and research questions so as to bring the sound finding. The researchers also designed exploratory survey research design to explore the perceptions of ELT teachers on CLT, and they selected 30 EFL teachers from Tunisian secondary schools by selecting the volunteered teachers who were interested to take part in the study as the participant. They used open ended and close ended questionnaires as data collection instruments, and they apply questionnaires appropriately even though it is not recommended to use only a single instrument to get reliable and valid responses from the participants. The combinations of both quantitative methods and qualitative methods of data analysis technique are used to analyze the collected data. At last, the researchers forwarded the sound conclusions for the teachers' perceptions and implementations of CLT in the classroom, and they left the study open for other further studies by inviting other interested researchers on the issue.

But, it doesn't mean that the study is purely appropriate because it lacked some interesting constituents. For instance, the study selected only one sided title on perceptions of teachers; only one instrument was used; the samples were not representative to conclude; they used non probability sampling and the procedures were not appropriate enough to collect the necessary data. These all are said when I evaluate this article. Please bear in mind that, in my evaluation, I have just forwarded what I feel. It may not be correct, but as I sense, I have tried to evaluate it in my perspectives as far as my understanding on the research is concerned.

\section{Analysis Two: EFL Teachers' Attitudes towards Communicative Language Teaching in Taiwanese college}

\section{Reviewing general introductions and statements of the problem}

This explanatory article was conducted by Ming Chang in 2011. Ming Chang was born in Tainan, Taiwan. She earned her Ed.D from Texas A \& M University Kingsville in USA. Now she is an Assistant Professor in Language Teaching Center at Minghsin University of Science and Technology in Taiwan. Her research interests include TEFL and EFL teacher training. In this section, I am going to review the second article by using the criteria and the frameworks which are used in the first article review, and I also analyze the second study by comparing and contrasting with the earlier article. Therefore, I have to do dual tasks at the same time; reviewing 
the article by using the criteria used earlier and comparing and contrasting this article with the first one.

The title, like that of the first article, is very interesting and crucial issue in the current trends of teaching learning situations of English by using CLT method. Because of the current situations, it is challenging to apply CLT due to different obstacles. EFL teachers have good feeling towards CLT in to apply in the classrooms, but numerous variables face them to sustain the intended method, CLT. Therefore, the title is current issue to be studied in the form of research. Like the above article, the title it focuses on the perceptions of Taiwanese college EFL teachers' perceptions and the actual practices on CLT in the classrooms. Like the first article, the title of this article was narrow and one sided. That means, the study focused only on the teachers' perceptions and practices towards CLT. The students' perception also should have incorporated in the study. If I were the researcher in this situation, I would conduct on teachers' and students' perceptions and actual practices on CLT in the classrooms, because students are the major subjects to be studied so that problems would be assessed. It was nice if the researcher included the students' perception so as to make the study complete, and by incorporating both the students' and teachers' perceptions and practices, I would have conducted a valid and reliable research.

The researcher was initiated to study this study by the review of previous literature showing that although teachers' attitudes played a crucial role in revealing their thinking about CLT and their implementation of CLT in the classrooms, there were constraints to apply CLT in practice in a particular EFL setting, Taiwan. The first article was motivated by actual experiences of the problem whereas this article was motivated by the review of the literature which focused on the perceptions and the practice of CLT in the classrooms.

As a good article, this study summarized the overall concepts in abstract, and introduced the nature of CLT in the background. Particularly, the abstract dealt with very important and critically summarized points which are emanated from the entire sections of the study. It pushed the readers to finish the whole study since the abstract was very interesting and attractive. In relation to its introduction, the authors introduced the title by stating the natures and principles of CLT by incorporating the authors; ideas on the natures and practices of CLT, and then She moved to their specific issue on perceptions and challenges to implement CLT. 


\section{Reviewing research questions and objectives}

The study forwarded two research questions to answer at the end of this article. Those research questions were constituted by considering quantitative and qualitative studies to reach on the appropriate conclusions and findings. These were the research questions:

1. What are Taiwanese college teachers' overall attitudes toward Communicative Language Teaching?

2. What are the reasons underlying the teachers' attitudes toward CLT?(p. 8)

Like the earlier article, the research questions are clear and researchable for the topic. These questions enabled the researchers to formulate appropriate objective for the successful completion of the study. The questions raised the perceptions of EFL teachers and the challenges to implement it in the classrooms.

The first question dealt with the perceptions of the teachers on the communicative language teaching while the second one focused on the reasons underlying the teachers' attitudes toward CLT in their classrooms. Similarly, the research questions of the two articles were appropriate, clear and researchable. Therefore, I do not have any grievances with the basic questions; they were well done.

The main purpose of this study was to examine Taiwanese college teachers' attitudes toward CLT and the rationales underlying their attitudes toward CLT. The study also aimed at investigating the reasons behind attitudes the teachers held toward CLT.

The research objectives were directly matching with the research questions. The stated objectives were clear, researchable and appropriate to forward the study into its findings. The author formulated manageable and achievable objectives so as to get a good conclusion at the end. With respect to the earlier article, the objectives in both articles were smart and well designed. Even, the questions were more appropriate than the title because the objective focused on both the teachers' perceptions and the challenges to implement CLT in the classrooms of Taiwanese colleges. Therefore, I have no more weak sides on the objectives of the study.

\section{Reviewing the methods of the study}

Like the earlier study, the methodology covers the research design, the participants, sampling size and sampling techniques, data collection instruments, data collection procedures and method of data analysis. 
Unlike the above study which was analyzed in part one, an explanatory mixed method (which includes first quantitative data collection with qualitative data collection) was used in the study. This was the main difference that the earlier study was exploratory survey research design where as this study was explanatory research design. As far as my knowledge is concerned, the main distinguishing aspect among researches is the research design. The research design affects the study by using its own procedures and methods. The ultimate purpose of explanatory research design is to explain, to investigate and to assess the current problems and trends by describing the nature of the problem so as to get conclusions on it. Thus, the research design is appropriate with the research questions, objectives and findings in general.

The populations of this study were Taiwanese college EFL teachers in southern Taiwan colleges setting. Among those populations, the sample size constitutes 55 EFL teachers who were randomly selected to be the participants of the study. Those 55 participants were selected to respond for the questionnaires. The participants of the study were selected by using cluster sampling by dividing and giving probability chance for the college in southern Taiwan first, and teachers were selected by using simple random sampling. Additionally, 8 participants (four teachers from each two colleges) from those 55 participants were selected for the interview to explain the quantitative data.

Having got this evidence, the selection was appropriate and it was good to reach on conclusions by getting diversified responses from the participants who were selected randomly. Even though we cannot say probability sampling is always better, probability sampling is appropriate in this type of study. However, the participants were too few to conclude the study and to reach in to sound finding. They were not fully representative enough to make generalizations. Assume, there are many colleges in Taiwan, among those colleges, only two southern Taiwan colleges were selected and teachers were selected from those two colleges in one geographic areas of Taiwan. Therefore, it was not appropriate to get enough and diversified data from the respondents because they had the same institution and even they had similar geographic area. The study also used cluster sampling which is a part of probability sampling technique, and it applied appropriate sampling technique to reach on valid conclusions.

With respect to the above study, this study was better than that of the former study by its sampling size and sampling technique. This study took 55 EFL college teachers where as 30 EFL teachers were taken in the former study. The former study (the Tunisian article) used non 
probability sampling while this study applied probability sampling. In my point of view, this study was more appropriate than the former study because we can get more reliable and valid data from this study in which probability sampling was used. If we use probability sampling technique, we have tendency to get heterogeneous responses from different participants. To sum, this study was more appropriate than that of the first article based on its sampling size and sampling technique.

Furthermore, this study used questionnaire and interview to collect data from participants. The study constituted 24 close ended questions by using likert scale. A five point likert scale format questionnaire was used to investigate the participants' attitudes toward principles of CLT. The quantitative data from questionnaire were explained by using interview. Face to face and semistructure interviews were conducted in order to investigate the complexities of the participants' perceptions and experiences. During the interviews, the researcher asked the interviewees predetermined, open-ended questions, but allowed flexibility concerning follow up questions. The qualitative interview questions were used to get extra data from the participants. They supported their close ended questionnaires by using open ended semi structured interview questions to confirm their responses in the questionnaire.

It was strong side of the study for using two data collecting instruments like questionnaire and interview. With compared to the former study, the current study was appropriate and reliable because the former study used only questionnaire whereas this study applied questionnaire and interview.

On the contrary, the current study used only close ended questions, and the questionnaire even did not have any introduction and directions about the respondents and the questionnaires whereas the former study had both open ended and close ended questions to be responded both qualitatively and quantitatively respectively. Besides, the former study gave very clear introduction and direction how to handle the questionnaires even though it did not apply for interview for the participants to triangulate the data by using different tools. As I have seen the appendixes of the two comparative studies at the end, the former Tunisian article had a clear instruction and introduction that the current study. The good thing I had seen in this study was it incorporated interview which was not found in the former one, but it was not still fully acceptable since the study should have used more instruments to get more valid and reliable data from the participants of the study. Instead, the author should have added observation or focus 
group discussion, and also instead of forwarding 24 similar likert scale questions, it would be better to make them variety as open ended. When I come across to the interview, semi structured interview was used to collect enough data from the 8 interviewees. The interview enabled them to explain the nature of the problem in advance. But, the interview questions were not found at the form of appendix at the end of the study.

In relation to its method of data analysis, the study used a combination of both qualitative and quantitative data analysis techniques. The study analyzed close ended likert scale questions by using quantitative methods of data analysis technique in percentages, numbers, mean, mean deviation and standard deviation in the form of table. On the other hand, open ended semi structured interviews were analyzed by using qualitative method of data analysis technique in the form of expressions, discussion, narrations and descriptions. Qualitative analysis was carried out through an analysis of the results of the open ended interviews.

Having gained information above, both studies used mixed methods of data analyses to interpret the data well. Using both quantitative and qualitative methods of data analyses is helpful to get additional data towards the conclusions. Even though the former one used only questionnaire, it included both open ended and close ended questions to analyze; that was why it used mixed method of data analyses techniques. Similarly, the current study used mixed method of data analyses techniques since it applied close ended questionnaires and open ended interviews to be analyzed quantitatively and qualitatively respectively. To sum, both studies used appropriate method of data analyses techniques to analyze the collected data from the participants either in questionnaires or in interviews.

Generally speaking, concerning to the methodology of the study, this study included important points so as to make the studies reliable. The methodology went with the objectives and the research questions to reach on to the findings. It was clear enough that it clearly stated the participants, the research design, the sampling size and techniques, the data collection instruments and finally the method of data analysis techniques in advance. And also, both studies had shared some similar features particularly in methodologies.

\section{Reviewing the study findings}

Based on the finding, EFL teachers had positive attitudes and perceptions towards CLT. Participant teachers expressed their perceptions and attitudes towards CLT in classrooms. For instance, the researcher concluded the participants' suggestions under. 
The findings demonstrate that CLT can make English teaching meaningful and interesting. Teachers dislike using traditional grammar teaching that requires the students to memorize numerous grammar rules. Instead, the teachers stated that CLT assists the students to comprehend linguistic forms and use these rules for communication. From the teachers' perspective, communicative activities are helpful for the students to practice rules in meaningful contexts. In addition, different from the grammar translation method focusing merely on reading skills, CLT considers all four skills as integrated skills, which should not be taught separately. Further, CLT creates a non-threatening language environment that lowers the learners' anxiety and make class input comprehensible. Finally, in CLT, both students and teachers play different roles than those in the traditional classrooms. Instead, students take the initiative and responsibility for their own learning; they can explore knowledge themselves and find their own answer. (p.13).

In the aforementioned findings, I understand that the perceptions of the EFL teachers' on CLT are assessed appropriately. The finding corresponded with the objectives and the questions; it was directly linked with the objectives. Basic questions were answered in accordance with the objectives of the study. The researcher accomplished her study successfully in relation to objectives because she tried to answer the research questions and the objective of the study. The finding forwarded important conclusions and implications based on the questions raised before. On the contrary, from two basic questions, only the first one was answered on the finding, but the second one was not articulated. For instance, the second research question dealt with the behind challenges to implement CLT in the classrooms, but the finding did not answer it well. It only focused on the perceived perceptions of EFL teachers' on CLT. This basic question should be answered properly in the findings, and also it was true for the second specific objective which dealt with investigating the challenges of teachers' implementation on CLT.

Frankly, the study finally invited other researchers to study on this issue since it was not properly done inclusively. By pointing the limitations of the study, Chang recommended to conduct other studies in the same topic.

This study recommends possible directions for future studies. First, the participants in the study are from two universities in southern Taiwan; thus, the results cannot be generalized to other educational contexts. Further studies may include teachers from 
universities from other EFL contexts. Additionally, teachers' attitudes are based on the teachers' self-report in the study. Future studies are recommended to examine teachers' CLT practice in more detail and to examine closely how teachers' attitudes towards CLT influence their practice of CLT. (p. 13)

Generally speaking, the researcher tried to conduct this study in a good manner so as to explain the current trend, situation and problem in the form of explanatory research design. This study was nearly the same with the former on by its conclusion and findings. They both focused on the perceptions of the EFL teachers on CLT in the classrooms, and challenges to implement in the classrooms. The difference is that the studies were conducted in different setting; they had different research design; they used different instruments; they applied different sampling techniques, and they selected different sampling sizes in number. Otherwise, they were the same in other aspects. They gave good abstract, introduction, key words and conclusions. They also reviewed others' works and studies properly. The reviews of related literatures were extensive to explain the nature of the problems.

\section{Analysis Three: Teachers' perceptions and challenges regarding the implementation of communicative language teaching (CLT) in Malaysian secondary schools}

\section{Reviewing general introductions and statements of the problem}

This article was published by Reza Raissi and Fazirah Mohd in 2013. The researchers were interested to conduct the studies on communicative language teaching and related issues. They have also published other journals and articles in EFL teaching learning processes. They have worked in Faculty of Education, Universiti Teknolgi, Malaysia.

In this article review, I am going to review the study by using the general frameworks or criteria which are used in the above two articles, and I want to analyze the article by compare and contrasting it with the former two articles, like I did in the second part. Therefore, instead of presenting the third article separately, I am going to reflect my own suggestions by collaborating, comparing and contrasting this article with the above reviewed articles which focused on the same research title.

Starting from the title, it is interesting issue and it includes the perceptions and the challenges of Malasyian EFL teachers of secondary schools. It focused on the attitudes and the challenges to implement CLT in Malasyian secondary schools. Relatively, from the above studies, the title of 
this article is more inclusive that the above studies. The above studies titled only on the perceptions but, this study focused on the perceptions and the challenges to implement CLT.

Like the above mentioned articles, this article had a good abstract and introduction. It ignited the readers by forwarding very important points and summaries on abstract, and it introduced the general features and the natures of the problem briefly.

The researchers were motivated to conduct this study by directly experiencing the problem when they assessed the secondary schools of Malaysia. Like the first Tunisian article, by observing the actual problem, they were initiated to conduct it.

\section{Reviewing research questions and objectives}

The ultimate purpose of this article was to investigate teachers' perceptions and challenges regarding CLT in Malaysian secondary schools. This general objective includes another specific objective. Another specific objective of this article was to investigate the effectiveness of CLT method seems necessary in the context of Malaysia. The objectives are clear and achievable by the researchers. With respect to the above article, the objectives are appropriate to conduct the study on CLT. These objectives were directly related to the title of the study, and they led the researchers towards the conclusion by collecting reliable data from participants.

On the contrary, this study did not have any research questions to answer. Without the basic questions, it was impossible to conduct the study because they are frameworks that guide the overall study. The above studies had research questions that moved the study forward towards the conclusions, but this study did not have questions. Probably, the main distinguishing element this study from the above ones is the research design. This study is purely qualitative research where as others were exploratory and explanatory research. Actually, basic questions are not mandatory in qualitative research design, and the researcher will formulate implicit questions which are linked with the objectives of the study. The researchers could conduct this study by using objectives, and they moved to the findings.

\section{Reviewing the methods of the study}

In this study, the research design, participants, sampling size, sampling technique, data collection instruments and method of data analysis are presented.

In this study researchers used a qualitative research design in which they have used semistructured interviews to collect the required data. Participants of the study were 30 ESL (English 
as Second Language) instructors who taught general English courses in the secondary schools of Malaysia, and all of them were female. Participants of the study have been selected based on stratified purposeful sampling. (p. 4).

In the above extraction from the current article, this study is purely qualitative research design. It was totally different form the above studies since it is qualitative research. The former article was exploratory research while the second was explanatory. The study also they used semi structured interview to collect qualitative data from the participants. Since it was qualitative in nature, it applied interview for data collection purpose. Interview was appropriate for this study, but it should not be only one instrument; instead, other instruments should be incorporated like observation and open ended questionnaires to collect reliable data from the participants of the study. The first study used only questionnaires which contained close ended and open ended questions, where as the second one used questionnaires and interview. This study used only interview to collect data from the interviewee. It was appropriate if the researchers used other data collection instruments to triangulate the data.

The populations of the study were Malaysian secondary school ESL teachers. Among those total populations, the authors selected 30 ESL female teachers for interview. Those 30 ESL female teachers were selected by using stratified purposive sampling. In this case, the participants were not representative for all ESL Malaysian secondary school teachers because the numbers of the participants were very few; the participants were all females and they were selected by using stratified purposive sampling. These are the limitations of this study.

When I compare this study with the above ones, they are different in their methods. For instance, the first study had 30 participants who were selected purposively; the second article had 55 participants who were selected randomly, and this one used stratified purposive sampling in different strata. However, the above two studies selected both female and male EFL teachers, but this study selected only female ESL teachers. One type of category or stratum will not give valid information to conclude the finding of the study. The researchers should have included male ESL teachers so as to get diversified data from the interviewees. When compared with the above ones. This study was not as such appropriate due to its limitations.

Furthermore, since this study is qualitative research, its data had been analyzed qualitatively. A qualitative data analysis technique was used to analyze and interpret the data. For example; "Because of the importance of this issue a qualitative method was used in the study in order to 
investigate teachers' perceptions and challenges regarding CLT in Malaysian secondary schools. " (p.1).

This study was different from the above ones in its data analyses techniques. The above two articles used both qualitative and quantitative methods of data analyses, but this one used only qualitative method of data analysis. Actually, it should use qualitative method since it was qualitative research. The data analysis technique was appropriate and went along with the research.

\section{Analyses of findings and conclusions}

In relation to its findings, this study summarizes the conclusion as follow.

From the above discussion we can make conclusion that although Communicative Language Teaching (CLT) has been recognized as an effective method in language teaching and learning but still it seems difficult to apply this method in an ESL context like Malaysia. We can name some problems like lack of facilities in the Malaysian secondary school as they need to apply authentic tasks which relates to the students' real life situations, but they were not satisfied with the school facilities. On the other hand, most of the teachers didn't agree with some principles of CLT and they believed that still CLT principles cannot be applied in the secondary schools properly. At the end of study researchers became to the conclusion that CLT is an appropriate and favorable method of language teaching in Malaysian secondary schools but it should be adopted to a context of Malaysia, in a way that some useful techniques of this approach may be combined by some techniques of other old approaches of language teaching like Grammar Translation Method (GTM) to be applied in the mentioned class. (p. 9).

From the give conclusions, I can infer that teachers were not fully interested in CLT. Due to students' resistances, teachers were obliged to use traditional explicit method of teaching grammar and translation in ESL classrooms. They were using those traditional ones with the CLT to make the students efficient in English language.

Another conclusion was teachers had got scarcity of authentic materials and facilities to run CLT properly. The study also concluded that the teachers had got challenges to implement CLT in the classrooms.

\section{Summary}


In this paper, I have evaluated three research articles which focus on the perceptions and practices of EFL teachers on CLT in different settings. After I have read these three articles repeatedly until I understand, I have examined their strong sides and limitations. When I evaluate, I have analyzed the first article by using the given domain which are commonly used. The second article has been reviewed by the domains; apparently, I compared and contrasted it with the first one. The third article has also been evaluated based on the given criteria and by comparing and contrasting with the above articles.

To this end, more or less, all the three articles were very interesting when I examined their titles. They studied similar issue and they were appropriate in nature. They had clear objectives, researchable questions, appropriate methods and inevitable conclusions. They tried to answer the questions which were raised in each articles, and the questions and objectives were going along with the overall research findings. They reached in to sound findings that forwarded some sort of knowledge and experiences in to the problems. In general, those studies were appropriate and reliable in their research titles, objectives and findings.

Having mentioned the string sides, on the contrary, they had limitations. They sometimes lacked questionnaires specifically in article three. The participants were unrepresentative so as to conclude and generalize the overall population by taking only few participants which were selected even by using non probability sampling. Although it is difficult to choose one of the sampling techniques, according to our purpose, we can choose one of them. But, in these articles, probability sampling like the second article should be selected so as to get sound findings. They even used a single instrument in article one and three. Single instruments will not yield good data to conclude the study. Instead, different tools should be used to triangulate the data so as to get sufficient data from the respondents. In relation to their findings, they went along with the objectives and the research questions, and they invited other interested researchers for further studies in the same issue. Therefore, the articles were appropriate though they had limitations.

Generally, these studies, more or less, had some strong sides and also limitations. In relation to its strong side, it contains a good title with the brief introduction of the authors, good abstract, key words, objectives, questions, methods and findings whereas lack of triangulation, using only one instrument, selecting unrepresentative participants and using purposive sampling dominantly were the limitations.

\section{Conclusion and implications for TEFL}


ELT or TEFL teachers in modern sense are facilitators of the teaching learning processes in EFL classrooms as English is being taught as a foreign language, like Ethiopia. Since it is the foreign language for Ethiopia, different problems which are related to teaching and learning processes are emerging. In order to handle those problems, TEFL teachers should conduct researches so as to investigate problems or to solve practical problems in the classrooms. Before TEFL teachers conduct language researches, we should first read and evaluate plenty of research papers, journals, articles, seminars, theses and dissertations. In order to evaluate language studies, we should also have frameworks to evaluate.

For instance, we evaluate research articles by focusing on the title, abstract, introduction, statement of the problem, research questions, objectives, research design, participants, sampling size, sampling techniques, data collecting instruments, methods of data analyses and findings based on our perspectives and the general guideline principles how to conduct social researches. By evaluating those research related papers, we will have experiences, knowledge and skills to conduct reliable and valid researches and studies.

In order to review articles higher order skills; like, analysis, synthesis and evaluation are very important to judge whether the articles are appropriate or not. We have to be critical enough to evaluate researches in advanced way. By using these reviewing skills, we can evaluate, analyze and review research journals. This review is very important for TEFL teachers and TEFL students so as to conduct our MA thesis proposal and final paper.

Finally, if we are in the journey of this profession, as a TEFL teacher, we have to conduct researches to solve practical, to investigate problems and to evaluate articles, programs and text books. We should always be researchers in EFL teaching learning processes. If we are researchers, we will be even proud of our profession since we solve numerous problems.

\section{References}

- Asma, Ounis \& Tesnim, Ounis (2017). Tunisian Secondary EFL School Teachers' perceptions regarding Communicative Language Teaching: An exploratory survey. International Journal of Humanities and Cultural Studies ISSN 2356-5926. Volume 4 Issue 1 June 2017.

- Ming, Chang (2011). EFL Teachers' Attitudes toward Communicative Language Teaching in Taiwanese College. Asian EFL Journal Professional Teaching Articles Volume 53 July 2011. Minghsin University of Science and Technology, Taiwan. 
- Reza Raissi \& Fazirah Mohd (2013). Teachers' perceptions and challenges regarding the implementation of communicative language teaching (CLT) in Malaysian secondary schools. Proceeding of the Global Summit on Education (GSE2013). Kuala Lumpur. Malaysia. 